\title{
O GRUPO DE ESTUDO-REFLEXÃO PERSPECTIVA TEÓRICO- METODOLÓGICA PARA FORMAÇÃO CONTINUADA: UM ESTUDO COM GESTORES PÚBLICOS DE EDUCAÇÃO ESPECIAL
}

\author{
EL GRUPO DE ESTUDIO-REFLEXIÓN PERSPECTIVA TEÓRICO- \\ METODOLÓGICA PARA LA FORMACIÓN CONTINUADA: UN ESTUDIO CON \\ ASESORES PÚBLICOS DE EDUCACIÓN ESPECIAL
}

THE STUDY-REFLECTION GROUP AS A THEORETICALMETHODOLOGICAL PERSPECTIVE FOR CONTINUING EDUCATION: A STUDY WITH PUBLIC MANAGERS OF SPECIAL EDUCATION

\author{
Mariangela Lima de ALMEIDA ${ }^{1}$ \\ Rayner Raulino e SILVA ${ }^{2}$ \\ Janaina Borges ALVES ${ }^{3}$
}

RESUMO: Este texto focaliza o debate acerca da formação continuada de gestores e professores da educação com vistas a garantia da escolarização de alunos com deficiência, transtornos globais do desenvolvimento e altas habilidades/superdotação. Aborda o panorama dos movimentos e políticas em prol da inclusão escolar, dando destaque para pesquisas que tomam como objeto a formação e atuação de gestores públicos de Educação Especial. Analisa elementos que constituem um grupo de estudoreflexão de gestores-pesquisadores e pesquisadores-acadêmicos que se dedicam a compreender os possíveis para a constituição de políticas de formação continuada na perspectiva da inclusão. $\mathrm{O}$ estudo em tela, assume como referencial teóricoepistemológico a pesquisa-ação colaborativo-crítica e as teorizações de Jürgen Habermas. O percurso do grupo é retomado a partir de diálogos presenciais e virtuais, registrados em diários de campo, relatórios de reuniões, transcrições dos encontros do grupo e dos seminários promovidos. Reflete elementos metodológicos que marcam a trajetória constitutiva desse grupo e problematiza o lugar do pesquisador na construção de conhecimentos sobre formação continuada. O processo vivido evidencia a possibilidade de uma perspectiva crítica da formação continuada promovida por meio de grupos de estudo-reflexão.

PALAVRAS-CHAVE: Formação continuada. Gestores públicos de educação especial. Pesquisa-ação colaborativo-crítica. Grupo de estudo-reflexão.

1 Universidade Federal do Espírito Santo (Ufes), Vitória - ES - Brasil. Professora Adjunta do Departamento de Educação, Política e Sociedade, do Programa de Mestrado Profissional em Educação e do Programa de Pós-Graduação em Ensino, Ed. Básica e Formação de Professores. E-mail: mlalmeida.ufes@gmail.com.

${ }^{2}$ Universidade Federal do Espírito Santo (Ufes), Vitória - ES - Brasil. Discente do PPG em Educação. Bolsista Capes/DS. E-mail: raynerraulino@gmail.com.

${ }^{3}$ Universidade Federal do Espírito Santo (Ufes), Vitória - ES - Brasil. Discente do Curso de Pedagogia. Bolsista PIBIC/UFES. E-mail: janainaborges25@live.com. 
RESUMEN: Este texto destaca el debate acerca de la formación continuada de asesores y profesores de educación con el objetivo de garantizar la escolarización de alumnos con discapacidad, transtornos globales del desarrollo y altas habilidades/superdotación. Aborda el panorama de los movimientos y políticas a favor de la inclusión escolar, dando destaque a las investigaciones que toman como objeto la formación y actuación de asesores públicos de Educación Especial. Analiza elementos que constituyen un grupo de estudio-reflexión de asesores-investigadores $e$ investigadores-académicos que se dedican a comprender las posibilidades para la constitución de políticas de formación continuada en la perspectiva de la inclusión. El estudio en análisis, asume como referencial teórico-epistemológico la investigaciónacción colaborativo-crítica y las teorizaciones de Jürgen Habermas. El recorrido del grupo es retomado a partir de diálogos presenciales y virtuales, registrados en diarios de campo, informes de reuniones, transcripciones de los encuentros del grupo y de los seminarios promovidos. Reflexiona elementos metodológicos que marcan la trayectoria constitutiva de ese grupo y problematiza el lugar del investigador en la construcción de conocimientos sobre formación continuada. El proceso vivido evidencia la posibilidad de una perspectiva crítica de la formación continuada promovida por medio del grupo de estudio-reflexión.

PALABRAS CLAVE: Formación continuada. Asesores públicos de educación especial. Investigación-acción colaborativo-crítica. Grupo de estudio-reflexión.

ABSTRACT: This essay is focused on the debate about continuing education of teachers and education managers that aims to guarantee schooling for students with disabilities, pervasive developmental disorder and high abilities/intellectual giftedness. It approaches the prospective of movements and policies in favor of education inclusion, focusing on researches that studies public managers of special education's training and performance. It analyses constitutive elements of a study-reflection group of managers/researchers and researchers/academics whom dedicate themselves to comprehend what is possible in the process of creating policies for continuing education in a inclusive perspective. This study has as theoretical-epistemological referential a critical-collaborative action research and Jürgen Habermas theorization. The group's courses is taken from presencial and virtual dialogs recorded on field notes, meetings' records, group meetings' transcription and promoted seminars. It reflects methodological elements that traces the constitutive path of this group and problematizes the researcher's place in the continuing education's knowledge construction. The process experienced enhance the possibility of a critical perspective of continuing education promoted by study-reflection groups.

KEYWORDS: Continuing education. Special education's public managers. Criticalcollaborative action research. Study-reflection group.

\section{Introdução}

Espaços de esperança aparecem de fato [...] qualquer que seja a razão de sua existência, tais espaços devem ser aproveitados estrategicamente. Eles oferecem encorajamento às forças da justiça, 
mas não são suficientes por si sós [...] devem ser tornados públicos. É preciso expandi-los [...] É necessário transformá-los em identidades coletivas (McLAREN, 2000, p. 12, grifo nosso).

Entre a descrença e a esperança neste momento da história brasileira, concordamos com McLaren (2000), que são nos pequenos espaços de esperança que a humanidade vai delineando movimentos que se instauram para transformar estruturas postas e que não mais atendem aos anseios da sociedade. Dessa forma, os homens organizam-se coletivamente, a fim de proporem ações dirigidas, reivindicando por melhores condições de vida. Em sua evolução, vão construindo novos rumos para as gerações futuras.

É fato que vivemos atualmente em "tempos de crises": da crise da razão à crise do conhecimento; da crise econômica à crise da moral; da crise familiar à crise da diferença. $\mathrm{O}$ momento é de crise, é crítico e, portanto, propício à crítica, à reflexão necessária que pode trazer-nos de volta à possibilidade de transformação da mentalidade humana. Das crises que marcam o século XX e se propagam neste século, os desafios postos as questões da Educação se configuram diante das marcas do positivismo, arraigadas nos modos de conceber a escola, e a eclosão de movimentos que buscam um outro paradigma para a pesquisa e as práticas educacionais.

A instituição escolar, marcada pela racionalidade técnica e pela eficiência industrial, estruturou-se “[...] em um modelo completo como especialização graduada do currículo, divisão sequenciada deste ao longo da escolaridade e classificação dos estudantes em "fases para sua transformação" (SACRISTÁN, 2002, p. 25). Temos, assim, uma escola desenhada para promover a homogeneidade e negar a diversidade inerente à pessoa humana. Uma escola que, embora se expanda por meio de um processo de "universalização do ensino", contribui ainda para a manutenção da exclusão dentro de seus muros, por meio de metodologias descontextualizadas e descompassadas, programações lineares, temporalidade inflexível e categorias, como de sucesso e insucesso, normalidade e anormalidade, atraso e fracasso escolar.

De acordo com os estudos de Ferraro (1999, p. 39), o mapa da exclusão na escola no Brasil, ou seja, os alunos em grande defasagem idade/série, constitui-se num panorama alarmante. Por mais longe "[...] que possa levar a sua autonomia, a escola é tanto mais excludente quanto mais o é a sociedade à qual serve".

No contexto regido pela homogeneização, a educação tem construído e sustentado modos de ser/estar como aluno e como professor. De um lado, a escola tem 
produzido o "não-aprender", institucionalizando o "aluno-não" para justificar o "nãoensino" a partir de uma suposta "não-aprendizagem" (MOYSÉS, 2013). O aluno, constituído por seus múltiplos sentidos, na medida em que não responde aos padrões prefixados pela homogeneização e pela padronização, é instituído como "aquele que não aprende na escola".

Observa-se que, para muitos profissionais da educação, as causas do fracasso escolar se centram nas crianças e em suas famílias. A instituição escolar é, na concepção desses atores, isenta de responsabilidade. "A escola, o sistema escolar são sistematicamente relegados a plano mais que secundário quando falam sobre o que consideram causas do fracasso escolar" (MOYSÉS, 2013, p. 30). As justificativas para o não-aprender estão sempre centradas nos fatores biológicos do sujeito, negando sua identidade sociocultural, que, por sua vez, se institui também no cotidiano da escola.

No entanto, é preciso considerar que as práticas homogeneizadoras na escola e a institucionalização do "não-aprender" retratam uma determinada concepção sobre o conhecimento e a formação docente. Habermas (1987a, p. 146) esclarece que a concepção positivista do conhecimento "[...] tende antes a substituir a ação ilustrada pelo controle técnico". $\mathrm{Na}$ concepção da racionalidade técnica, os profissionais rigorosos solucionam problemas instrumentais claros, com a aplicação da teoria e da técnica derivadas de um conhecimento sistemático, de preferência científico. $\mathrm{O}$ professor é visto como um técnico que deve colocar em prática as regras e estratégias científicas e/ou pedagógicas.

É no século XX que temos movimentos que buscam um contra-script desse panorama. O movimento de inclusão escolar ganha sustentação político-ideológica no cenário internacional a partir da década de 1990. Princípios de aceitação das diferenças individuais, valorização pessoa, convivência dentro da diversidade humana, aprendizagem por meio da cooperação são incorporados por conferências e documentos internacionais ${ }^{4}$. No Brasil, as reformas educacionais ganham um discurso esperançoso decorrente dos direitos sociais conquistados na Constituição Federal de 1988 (MENDES, 2010). A Lei de Diretrizes e Bases da Educação Nacional - LDBEN nº. 9.394/96, marca no Brasil de modo mais significativo a constituição de projetos para as escolas tornarem-se espaços inclusivos. Assim, nos anos noventa, as políticas nacionais

${ }^{4}$ Conferência Mundial de Educação para Todos (1990); Declaração de Salamanca. Sobre Princípios, Políticas e Práticas na Área das Necessidades Educativas Especiais (1994); Convenção sobre os Direitos das Pessoas com Deficiência (2007). 
são desenhadas a partir da proposta de inclusão escolar, no fluxo de documentos internacionais (UNESCO, 1994) que enfatiza como público alvo para Educação Especial pessoas com necessidades educacionais especiais.

No percurso da história, em 2001 a Resolução CNE/CEB n 2 institui as Diretrizes Nacionais para a Educação Especial na Educação Básica, destaca em seu artigo $2^{\circ}$ que:

\footnotetext{
Os sistemas de ensino devem matricular todos os alunos, cabendo às escolas: organizar-se para o atendimento aos educandos com necessidades educacionais especiais, assegurando as condições necessárias para uma educação de qualidade para todos (BRASIL, 2001).
}

Embora o termo preconizado pela Resolução de 2001 para definir o público-alvo da educação especial tenha trazido uma perspectiva conceitual transformadora, em 2008, os formuladores da Política Nacional de Educação Especial na perspectiva da Educação Inclusiva - MEC/SEESP/2008, destacariam que “[...] as políticas educacionais não alcançaram o objetivo de levar a escola comum a assumir o desafio de atender as necessidades educacionais de todos os alunos" (BRASIL, 2008, p. 15). Em sendo assim, o público-alvo da educação especial passa a ser os alunos com deficiência, transtornos globais do desenvolvimento e altas habilidades/superdotação. Em 2009, a Resolução n. 04 fixou normas para o atendimento educacional especializado para esse público, bem como destaca as atribuições do docente que realiza esse atendimento (BRASIL, 2009).

As diretrizes da política nacional desencadearam ações nos estados e municípios nos últimos anos. Observamos que as matrículas de estudantes público-alvo da Educação Especial na educação básica têm aumentado. O relatório “A Consolidação da Inclusão Escolar no Brasil” da Secretaria de Educação Continuada, Alfabetização, Diversidade e Inclusão - SECADI aponta com base no Censo Escolar MEC/INEP, uma evolução das matrículas entre os anos de 2003 até 2015. Vemos um aumento de matrículas na classe comum de " $425 \%$, passando de 145.141 estudantes em 2003 para 760.983 em 2015” (MEC/SECADI, 2016).

Assim, a matrícula do alunado da Educação Especial passa a exigir dos estados e municípios a proposição e implementação de políticas públicas que assegurem a educação dos sujeitos da educação especial no ensino comum. Desse modo, as políticas propostas e implementas pela gestão de Educação Especial tornam-se objeto de 
diferentes pesquisas. Segundo Pantaleão e Sobrinho (2014) é fundamental dialogar sobre os movimentos constituídos pela gestão de Educação Especial considerando "[...] as possibilidades e as tensões na implementação de políticas públicas que garantam, com qualidade, o processo de escolarização dos alunos sujeitos da Educação Especial" (PANTALEÃO; SOBRINHO, 2014, p. 6).

No contexto dos estudos sobre gestão em Educação Especial, temos nos dedicado nos últimos 05 anos a investigar os processos de formação continuada de profissionais da educação propostos e implementados pelos gestores públicos de Educação Especial em municípios e superintendências regionais de ensino (SRE) da região sul e serrana do Estado do Espírito Santo ${ }^{5}$. Este artigo dedica-se a refletir alguns dos movimentos construídos nesse estudo. Temos persistido na necessidade de construção de conhecimentos com o outro como possibilidade de constituição de ações formativas para gestores e professores que assegurem o direito aos processos de ensinoaprendizagem dos alunos público-alvo da Educação Especial. Nossa crença está na constituição de grupos de estudo-reflexivos, por meio da pesquisa-ação colaborativocrítica, como fundamentação metodológica e epistemológica para a constituição de políticas de formação continuada de profissionais da educação.

As bases epistemológicas e metodológicas dessa pesquisa-ação, estão alicerçadas na crítica-emancipatória e na colaboração entre pesquisadores e participantes. Nossa aposta está no diálogo e na colaboração entre Universidade e Redes de Ensino, pesquisadores da academia e pesquisadores da escola. Como propósito, “[...] temos buscado constituir processos de pesquisa que procurem superar os limites do racionalismo positivista e o relativismo desmedido do pragmatismo; assim, é possível pensar em alunos e professores como sujeitos de conhecimento" (ALMEIDA, 2010).

Esse processo é conduzido pela autorreflexão crítica e colaborativa. A teoria social crítica de Habermas é crítica no sentido de opor-se às disposições sociais contemporâneas erigidas pelo neoliberalismo. Deve desvelar os processos históricos que têm distorcido sistematicamente os significados subjetivos (CARR; KEMMIS, 1988). Essa crítica propositiva na pesquisa-ação ocorre essencialmente nas ações intersubjetivas partilhadas entre pesquisadores e participantes.

No cerne dos grupos, sustentamos processos de constituição de ações comunicativas e colaborativas entre gestores públicos de Educação Especial e

\footnotetext{
${ }^{5}$ A pesquisa possui financiamento CNPq (Edital 2014).
} 
pesquisadores da universidade, por meio de diálogos presenciais e virtuais, registrados em diários de campo, relatórios de reuniões, transcrições dos encontros do grupo e dos seminários promovidos ao longo do percurso.

A perspectiva de análise busca estabelecer um diálogo entre autores da literatura científica e autores do contexto - gestores e profissionais da universidade. Assumimos como premissa que:

No lugar do sujeito solitário, que se volta para objetos e que, na reflexão, se toma a si mesmo por objeto, entra não somente a idéia de um conhecimento lingüisticamente mediatizado e relacionado com o agir, mas também o nexo da prática e da comunicação quotidianas, no qual estão inseridas as operações cognitivas que têm desde a origem um caráter intersubjetivo e ao mesmo tempo cooperativo (HABERMAS, 2003, p. 25).

Nosso objetivo é, pela tessitura dessa discussão, refletir com os leitores, elementos que marcam a trajetória constitutiva desse grupo ao longo dos anos. Ao mesmo tempo, problematizamos a relevância da valorização do conhecimento produzido pelos profissionais que investigam suas práticas a partir do lugar instituído como pesquisador.

\section{Formação continuada de profissionais da educação para as questões da inclusão escolar: a pesquisa-ação como possibilidade}

Com os desafios e questionamentos postos em consequência dos processos inclusivos nas escolas comuns temos presenciado o aumento de ações voltadas para formação continuada de profissionais da educação no Brasil. Mesmo com avanços por meio de programas desenvolvidos na última década, a questão da formação de professores tem sido um grande desafio para as políticas governamentais, sendo esta uma barreira que se encontra também nas práticas formativas das instituições formadoras.

Com o incremento das políticas públicas de direitos das pessoas com deficiência, transtornos globais do desenvolvimento e altas habilidades/superdotação, o sistema educacional brasileiro passou a requerer novos formatos e ações que promovam processos educativos para o desafio de melhorar a qualidade da educação; além da qualidade, começa o debate para o acesso e permanência. Esse panorama passou a exigir outras perspectivas para a formação dos profissionais do ensino. 
As secretarias municipais de educação passam a atuar frente a novas demandas, em especial, os gestores da educação especial responsáveis pela articulação de programas que possam dar sustentação a inclusão desses alunos no ensino regular (ROCHA, 2016, p. 139).

Nesse sentido, estudos realizados nos últimos anos no Estado do Espírito Santo enfatizam a necessidade de iniciativas para a formação e atuação de gestores públicos de Educação Especial (GONÇALVES, 2008; RAMOS, 2011; BENTO, SILVA, 2015). As pesquisas destacam a relevância de novas formas de pensar a organização das políticas de formação continuada para Educação Especial, sendo este um dos grandes desafios colocados à esta modalidade de ensino, que como já dito, perpassa todos os níveis educacionais, principalmente diante das diretrizes propostas de inclusão escolar. Alguns desses estudos (GIVIGI, 2007; JESUS, 2012; JESUS, PANTALEÃO, ALMEIDA, 2015; ALMEIDA, 2013; ALMEIDA, ZAMBON, 2016) apostam na metodologia da pesquisa-ação colaborativo-crítica por meio de grupos de estudoreflexão entre gestores e pesquisadores como potência para a construção de conhecimentos e propostas para formação continuada de profissionais da educação.

No próximo item daremos ênfase à perspectiva dos grupos pela via da pesquisaação.

\section{A Pesquisa-ação e sua potência para a construção de grupos de aprendizagem}

São oferecidas algumas formações em meu município, porém muitas com palestras técnicas já pré-estabelecidas (GESTORA MUNICIPAL - QUESTIONÁRIO AVALIATIVO, 2014).

Reiteramos a fala da gestora, pois nos faz pensar em um modelo de formação que estamos "bem acostumados", o modelo técnico proveniente do paradigma da racionalidade instrumental. De certo modo, entranhado em nossa constituição profissional e em nossas práticas, temos dificuldade de nos desvencilhar dele, até mesmo quando desejamos muito, como tem sido nosso caso. Trilhamos as últimas décadas no debate acalorado por uma formação continuada de professores que se afaste das ideologias dominantes e que coloque o professor no lugar de sujeito de conhecimento. Por diferentes teorizações, pensar a pesquisa da prática docente, tornouse no Brasil e no mundo, condição essencial para a construção dos currículos de formação inicial e continuada de professores das mais diferentes áreas do ensino. 
Contudo, as práticas formativas e os estudos nessa área do conhecimento têm evidenciado o desafio de formadores e pesquisadores, em seus diversos lócus de atuação, em pensar e constituir meios para que essa formação, menos "técnica ou préestabelecida", aconteça de fato.

Em 2013 iniciamos um estudo apostando na possibilidade de constituir outros processos formativos a partir da pesquisa-ação colaborativo-crítica entre gestores/técnicos de Educação Especial e acadêmicos. Tiveram envolvidos profissionais de três Superintendências Regionais de Educação do Sul do Estado do Espírito Santo (SRE), vinte e sete Secretarias Municipais de Educação da Região Sul, além de professores, alunos da graduação e pós-graduação da universidade.

Das escolhas teóricas e epistemológicas optamos por sustentar nossa proposta de grupo de estudo-reflexão a partir dos pressupostos de Habermas. Partilhamos de suas ideias quando destaca as funções mediadoras da relação entre a teoria e a prática:

\begin{abstract}
A mediação da teoria e práxis pode apenas ser clarificada se iniciarmos por distinguir três funções, que são medidas em termos de diferentes critérios: a formação e extensão de teoremas críticos, que sejam consistentes com o discurso científico; a organização de processos de conscientização, nos quais tais teoremas podem ser testados numa única maneira pela iniciação dos processos de reflexão desenvolvidos no interior de certos grupos aos quais se dirigem estes processos; selecionar as estratégias apropriadas, a solução de questões táticas e a condução da luta política. No primeiro nível, o objetivo é fundamentos verdadeiros, no segundo, conclusões autênticas, e no terceiro, decisões prudentes (HABERMAS, 2000, p. 41, tradução nossa).
\end{abstract}

A partir de grupos focais realizados nas SRE's, os gestores iniciam o primeiro momento das funções mediadoras da relação entre a teoria e a prática, ou seja, a formação dos elementos teóricos.

Eu acho que agora a gente tá caminhando, a gente já saiu do momento da garantia de matrícula porque todos estão na escola. Nós estamos agora no viés da aprendizagem do sujeito e é isso que a gente tem tentado discutir (grifos nossos) (GESTORA MUNICIPAL - GRUPO FOCAL, 2013).

Que agora eles estão de fato dentro das escolas e o nosso desafio agora é a aprendizagem (grifos nossos) (GESTORA MUNICIPAL GRUPO FOCAL, 2013).

Das falas que emergem vemos que, a formação dos profissionais para a melhoria da qualidade da aprendizagem dos alunos com deficiência, transtornos globais do 
desenvolvimento e altas habilidade-superdotação, constitui-se como princípio fundante para os gestores.

Em dezembro de 2013, inicia os encontros do grupo de estudo-reflexão entre gestores e pesquisadores. A partir dele foi possível o início da organização dos processos de conscientização e de aprendizagem (segundo momento da função mediadora) no grupo. Esse primeiro encontro foi sem dúvidas um tanto desafiador, tanto para nós que estávamos propondo essa outra dinâmica de pesquisa-formação, bem como para os gestores. Inicialmente, enquanto grupo de pesquisadores-acadêmicos, tivemos dificuldade para organizar esse momento. Sempre acostumados com as metodologias e estratégias técnicas, pouco dialógicas, agora estávamos propondo construir uma comunidade de pesquisadores em conjunto com os gestores e para isso, precisávamos elaborar formas de mediação propiciassem a participação de todos, em todo o processo (HABERMAS, 2004).

Os gestores indagavam: "Mas o que vamos estudar aqui?"; "Quais conteúdos vamos discutir?"; “Quais os textos vocês vão nos indicar?"; "Quais atividades iremos ter que fazer?". Procurávamos exercitar uma premissa fundamental na organização dos processos de conscientização e aprendizagem proposto por Habermas (1987b): liberdade do discurso, ou seja, uma comunicação aberta e democrática. Os caminhos vividos ao longo desse processo podem ser organizados em três percursos: encontros realizados na Universidade, encontros virtuais e encontros nas SRE's.

O espaço-tempo do grupo permitiu-nos buscar, junto com os gestores, organizar o processo de aprendizagem do grupo, “[...] mediante processos de reflexão no próprio grupo" (CARR; KEMMIS, 1998). Apostamos na ideia dos pequenos grupos, na construção coletiva. A plenária como momento de debates, decisões e de consensos. O tema inicial seria a própria formação continuada.

Os encontros virtuais, oriundos de propostas dos gestores em pesquisas anteriores, em que sinalizavam a necessidade de constituição de um fórum de gestores públicos de Educação Especial. Essa demanda trouxe desafios para a equipe da universidade e gestores, frente ao desafio da tecnologia da informação e comunicação (TIC's). Inicialmente, a partir das demandas dos gestores, construímos um website para troca de informações e formação. Com o passar do tempo, percebemos que nossa maior necessidade não estava sendo atendida, assim foi criada a plataforma moodle ${ }^{\circledR}$ com a finalidade de permitir maior comunicação, diálogo e comunicação entre gestores e 
pesquisadores (SILVA, 2014; SILVA, ALMEIDA, 2014a, 2014b, RAMOS, CRUZ, SILVA, 2014).

Os encontros nas SRE's foram propostos a partir de julho/2014 como mola propulsora da aprendizagem do grupo em organizar sua própria aprendizagem, considerando o processo de autorreflexão organizada. Propusemos inicialmente um primeiro encontro. A partir desse momento, os gestores passaram a se organizar em um movimento que toma diferentes contornos em cada regional.

No geral, nos encontros do grupo, analisamos os princípios que fundamentam o processo de pesquisa-formação colaborativo-crítica; organizamos os processos de conscientização e da aprendizagem do grupo; refletimos criticamente conceitos e concepções de formação continuada; aprofundamos o conhecimento acerca da constituição dos projetos políticos de formação continuada e avaliamos o processo de pesquisa vivido. Esses momentos não ocorreram de forma linear e, sim, sustentaram todo o estudo.

Em meio à tensões e possibilidades, fomos experimentando estratégias, buscando nos afastar daquelas ferramentas diretivas, mecanizadas, pré-definidas e não reflexivas. Isso não significa que não houve organização do processo e sistematização. Foi preciso acreditar no que já temos, sem descartar as contribuições anteriores.

É necessário levantar o que já tem sido pensado em termos de formação continuada para, assim, traçar o melhor caminho para construir uma política de formação. [...]. Dar continuidade ao que já foi pensado e refletir sobre tudo o que já foi construído é economizar, é evitar erros antigos (GESTORA MUNICIPAL- DIÁRIO DE CAMPO, 2014).

O que tentamos foi lançar mão do diálogo, da colaboração e da autorreflexão crítica como princípios norteadores de todos dispositivos e estratégias que utilizamos, ou seja, grupos autorreflexivos preocupados por organizar sua própria prática à luz de sua autorreflexão organizada (CARR; KEMMIS, 1988).

A partir daí, realizamos seminários internos sobre a formação continuada e a gestão de Educação Especial, colóquios e seminários para o aprofundamento das temáticas de pesquisa-ação, formação continuada e gestão em Educação Especial. Nesses momentos, os participantes puderam compartilhar projetos de formação para os municípios constituídos ao longo desse processo de pesquisa. Além disso, contamos com a presença de professores e alunos de outras universidades brasileiras. 


\section{A constituição do pesquisador em um grupo de estudo-reflexão: caminhos formativos}

Compreendo que tal processo vem para desafiar os docentes a serem agentes de seu próprio percurso de formação (GESTORA MUNICIPAL - QUESTIONÁRIO, 2014).

Nesse item destacamos a constituição do "ser pesquisador" no grupo de estudoreflexão. Os dados expressam o processo desafiador para os pesquisadores-acadêmicos e para os pesquisadores-gestores. Um movimento de constituição, gradativo, pessoal, partilhado e colaborativo. Há um compartilhamento das angústias, demandas, concepções, busca por alternativas, etc. Esses movimentos foram constituídos nos diferentes espaços-tempos de diálogo constituídos: na universidade, nas SRE's e na plataforma moodle $®$.

As análises apontam que esse foi, sem dúvidas, um processo desafiador, tanto para os que estavam propondo essa outra dinâmica de pesquisa e formação, bem como, para os gestores participantes. Isso é retratado pelas atas de reuniões dos pesquisadores acadêmicos da universidade, quando expressam em relação à dinâmica dos encontros a serem realizados "[...] algumas ideias foram levantadas, mas nada foi conclusivo. Propostas podem ser levadas na próxima reunião" (ATA GRUPO DE PESQUISA, 2014). Além disso:

Fica acertado que todo o grupo de pesquisa precisa se aprofundar acerca das políticas de formação, elaboração de conceitos, formação continuada, entre outros (ATA GRUPO DE PESQUISA, 2014).

A formação propiciada no movimento da pesquisa-ação colaborativo-crítica exige um engajamento maior de todos os envolvidos, tanto na elaboração das propostas formativas, quanto nos aprofundamentos e estudos. Barbier (2007) destaca que a metodologia da pesquisa-ação não é para pesquisadores "mornos", nem para os preguiçosos, ou seja, exige muito desejo e aprofundamento em estudos. Além disso, requer a participação e interação de todos os envolvidos no processo, pois segundo Thiollent (1996) o pesquisador universitário, ao constatar um problema, tem que conduzir o grupo à problematização deste problema, possibilitando a partir de um contexto teórico um desenvolvimento maior dos sujeitos para que tomem consciência deste problema e busquem transformar essa realidade. Esse processo é reconhecido por Habermas (2002) como “formulação de teoremas críticos". 
Da parte dos pesquisadores-gestores vemos muito forte esse desafio pelo novo, pois a todo o momento nesse percurso inicial eles relatam a necessidade de uma formação diferenciada, ou seja, que saia do paradigma de uma formação técnica como tem acontecido em seus municípios, e percebemos que os gestores não só colocam isso em questão, como também demonstram o desejo de construir algo novo, como já foi relatado anteriormente e que tornamos a pontuar a partir de outros dados.

Estamos unindo os nossos saberes para construir algo novo, algo que pressupõe uma nova metodologia de formação (GESTORA MUNICIPAL - SEMINÁRIO DE GESTÃO, 2014).

Tudo aquilo que tínhamos como verdade fechada de formação, deve ressaltar que no início do nosso trabalho. Pensávamos que chegaríamos aqui e teríamos algumas apostilas com uma serie de conteúdos já formatados para que fossemos estudando, ou seja, com caminho traçado. Precisamos neste percurso desconstruir alguma coisa, que tínhamos como verdade enquanto processo de formação continuada [...] (GESTORA MUNICIPAL - SEMINÁRIO DE GESTÃO, 2014).

Participar de um grupo de formação na perspectiva da educação inclusiva exige de nós gestores uma busca constante de informações, maior aprofundamento acerca da aprendizagem e da construção do conhecimento, assim como informações básicas sobre tecnologia para favorecer uma melhor interação com o grupo. Minha disposição para participar dos diálogos do grupo é imensa, mas reconheço que para interagir de forma efetiva durante os debates preciso adquirir mais conhecimentos (GESTORA MUNICIPAL - QUESTIONÁRIO AVALIATIVO, 2014).

Identificamos a partir das narrativas dos gestores-pesquisadores, o receio de fazer parte desse processo, seja por sentirem-se inseguros diante do saber da pesquisa ou da teoria educacional. Dar-se aí outro desafio para os pesquisadores, pois nessa metodologia de pesquisa-formação, na perspectiva habermasiana assumida no grupo, é preciso aproximar/dar voz aos sujeitos e fazer com que eles se reconheçam como pesquisadores (HABERMAS, 1987b). Segundo Jeannet (1985) apud Barbier (2007, p. 45), esse processo é fundamental para que "vise sempre à uma mudança”, sendo este, o qual o reprimido saia de seu ciclo de repetições, o que nem sempre é fácil, por isso, se faz necessário a colaboração entre os pares, levando à uma transformação da realidade.

Acredito que este processo de formação que tenho vivenciado nos últimos meses é indispensável, pois parte de uma reflexão açãoreflexão-ação. Bem diferente de tudo que tenho praticado em minha vida profissional, estou vivenciando um processo de construção 
coletivo jamais vivenciado. Acredito, também, que esse processo de reflexão crítica nos permitirá enquanto educadores gestores avançarmos para um processo de transformação da prática pedagógica, a partir da nossa própria transformação. Embora tenhamos pouca autonomia para decidir as formações realizadas no âmbito da SRE, creio que é possível avançar um pouco mais nos processos de formação realizados no âmbito da Superintendência de Cachoeiro, principalmente no que se refere às parcerias com os municípios e no processo de escuta aos profissionais da educação especial (GESTORA MUNICIPAL - QUESTIONÁRIO AVALIATIVO, 2014).

Essa perspectiva de pesquisa-formação permite aos pesquisadores-gestores e pesquisadores-acadêmicos uma reflexão coletiva essencial para a sua formação, tendo em vista que, eles apontam, a todo o momento, que esse novo exige muita dedicação e estudo. Além disso, a partir dessa metodologia, se sentem mais preparados para agir em seus municípios, tendo uma nova postura, que os leva à refletir sobre a ação, bem como, saber se posicionar frente aos processos formativos. Portanto, apostam nesse processo de pesquisa-formação que os levou à construção de uma proposta política de formação para seus municípios de forma coletiva e que essa construção coletiva deu mais segurança na atuação dos gestores em seus municípios.

Uma coisa que eu gostaria de colocar aqui e penso que as minhas colegas do grupo também comungam do mesmo pensamento, que este projeto construído na coletividade dá uma segurança maior para o nosso fazer no município, uma segurança maior para o que nós queremos propor (GESTORA MUNICIPAL - SEMINÁRIO DE GESTÃO, 2014).

Esse processo de construção colaborativa ocorreu, também, por meio de diálogos virtuais, realizados em chat's na plataforma moodle ${ }^{\circledR}$, os gestores debaterem sobre os movimentos formativos em seus espaços de atuações para o desenvolvimento de políticas de formações continuadas para a promoção de uma educação inclusiva. Tais movimentos nos fazem pensar na necessidade em promover mudanças nos modelos de formação, fugir do tecnicismo, das formações tradicionais que não estimulem processos de inclusão.

Fiquei pensando no perfil dos profissionais que temos e acredito que necessitamos trabalhar o perfil do crítico reflexivo (GESTORA MUNICIPAL - AMBIENTE VIRTUAL DE APRENDIZAGEM, 2014). 
Penso que sensibilizar os profissionais do ramo da educação é o primeiro passo; uma vez que voltados aos acontecimentos do dia a dia faria com que pensasse diferente. E de certa forma teríamos mais apoio e credibilidade para trabalhar (GESTORA MUNICIPAL AMBIENTE VIRTUAL DE APRENDIZAGEM, 2014).

Esta sensibilização, penso que deve ser uma construção coletiva; pensar diferente envolve apropriação da realidade que se tem (GESTORA MUNICIPAL - AMBIENTE VIRTUAL DE APRENDIZAGEM, 2014).

Nesse movimento, percebemos a busca das gestoras em potencializar a mudança do perfil de professores de suas redes, para um pensamento mais crítico de sua realidade, mas essa mudança só será efetivada a partir da "sensibilização desses profissionais" para a compreensão das relações intrínsecas em seus espaços de atuação. "O desafio é formar professores que saibam buscar, na reflexão crítica da práxis e no entrelaçamento da teoria-prática, possibilidades para dialogar com a diversidade trazida pelos educandos para o contexto educacional" (ALMEIDA; VIEIRA; SILVA, 2013, p.876).

Os profissionais da educação em processos formativos podem estabelecer novos olhares em relação a sua própria prática, mediante "articulação de saberes”, "pequenos grupos" e entre outras possibilidades. "Refletir sobre a prática educacional, mediante a análise da realidade do ensino, da leitura pausada, da troca de experiências. Estruturas que tornem possível a compreensão, a interpretação e a intervenção sobre a prática" (IMBERNÓN, 2010, p. 43).

Portanto, nessa perspectiva, a escola e/ou a gestão pública tornam-se em ambientes interativos os profissionais participantes que precisam refletir sobre o seus fazeres numa consciência crítica-política, pois, suas ações estão diretamente relacionadas com o coletivo, ou seja, há mudança na própria realidade que influencia outros autores/atores participantes do mesmo contexto. O foco de uma proposta de formação na escola sai de uma visão individualista da formação contínua para uma aprendizagem coletiva, para que a inclusão do público-alvo da modalidade da Educação Especial não fique somente com o profissional, individualmente.

Conforme Dalben (2010), trata-se um processo de formação coletiva e cultural que leva à interação entre os sujeitos e tem como finalidade produzir conhecimentos e aprendizagens, entrelaçando suas histórias, sucessos, tensões, desafios e necessidades. 
As estratégias utilizadas pelo grupo provocam o desejo de buscar mais conhecimentos e oportunizam o confronto de opiniões. [...] A partir do diálogo, das discussões e da troca de experiências, somos convidados a todo tempo a refletir sobre qual o processo de formação continuada precisamos oferecer aos nossos educadores (RIO NOVO DO SUL QUESTIONÁRIO AVALIATIVO, 2014).

Isso nos leva a refletir que, para além de ser um processo desafiador, ele se faz necessário, pois, vemos que traz resultados positivos, e a formação carece disso. O trabalho por meio de grupos tem sido um grande suporte para essa pesquisa, pois todos podem partilhar coletivamente e racionalmente suas ideias e objetivos, convertendo-se em investigadores do processo (CARR e KEMMIS, 1988). E por meio dessa participação ativa dos sujeitos, pela via da racionalidade comunicativa presente no diálogo (HABERMAS, 1987b) nos grupos, eles tendem a perceber os problemas e juntos solucioná-los.

A pesquisa-ação deve incluir a participação ativa por aqueles que têm de realizar o trabalho na exploração de problemas que eles identificam e antecipam. Após investigação destes problemas o grupo toma decisões, acompanha e observa os resultados, bem como, realizam avaliações periódicas do processo. Além disso, o grupo decidirá quando algum problema fosse finalizado, ou não surtisse efeito, e a partir daí trariam para as discussões os problemas recém-percebidos (ADELMAN, 1993, p. 9, tradução nossa).

Portanto, apontamos o diálogo coletivo como forte da pesquisa-ação colaborativo-crítica, sustentada pelo agir comunicativo de Habermas (1987b), que tende dar voz aos sujeitos envolvidos e levar à um entendimento mútuo. Um processo que sustentamos na racionalidade comunicativa, a qual busca recuperar uma racionalidade esquecida pelo positivismo, tentando assim, recuperar o poder da autorreflexão contido no diálogo; para Habermas isso só é possível quando há um entendimento pelo próprio sujeito. O que Almeida (2010) defende que para essa autorreflexão acontecer e ter esse olhar diferenciado para as questões sociais e políticas, os participantes têm que estar engajados e comprometidos ativamente no processo.

\section{Considerações finais}

Os movimentos construídos no grupo de estudo-reflexão refletidos nesse texto, marcam a crença de profissionais, sejam da educação básica ou do ensino superior, na construção de conhecimentos com o outro como possibilidade de constituição de ações 
formativas que assegurem o direito aos processos de ensino-aprendizagem dos alunos público-alvo da Educação Especial.

Ao longo do processo vivido, fomos construindo dispositivos metodológicos, por meio da pesquisa-ação colaborativo-crítica, que sustentaram um percurso com muitos desafios, porém incerto. Era difícil nos deixar levar pelo outro, pelas dúvidas que pairavam quando não chegávamos à um consenso provisório. Contudo, esse mesmo desafio nos impulsionou a busca de entendimento mútuo, a compreensão do nosso lugar e do outro na pesquisa.

Sempre um movimento de idas e vindas, com avanços e retrocessos, mas que traz em sim um processo de aprendizagem único para todos envolvidos, pois a pesquisaação impõe ao pesquisador a implicação (BARBIER, 2007) pessoal, histórica, acadêmica, confrontando-o diariamente com seus modos de pensar e de agir. E, a partir do momento que assumimos a premissa fundamental da pesquisa-ação crítica - que os atores do contexto possam se converter em autores (CARR; KEMMIS, 1988) -, vamos construindo outros modos de produção de conhecimentos e outras formas de pensar/fazer formação continuada.

Assim, foi possível organizar com os gestores, um processo de conscientização e de aprendizagem no grupo, o qual, pesquisadores-acadêmicos e pesquisadores-gestores foram elaborando juntos novas propostas políticas de formação continuada para seus municípios, tendo em vista a formação pela via de um grupo de estudo-reflexão, com base na metodologia da pesquisa-ação colaborativo-crítica.

AGRADECIMENTOS: Conselho Nacional de Desenvolvimento Científico e Tecnológico (CNPq).

\section{REFERÊNCIAS}

ADELMAN, C. Kurt Lewin and the origins of action research. Educ Act Res, v.1, n.1, p. 7-24, 1993.

ALMEIDA, M. L. Uma análise da produção acadêmica sobre os usos da pesquisaação em processos de inclusão escolar: entre o agir comunicativo e o agir estratégico. 2010. 234 f. Tese (Doutorado em Educação) - Programa de Pós-Graduação em Educação, Universidade Federal do Espírito Santo, Vitória, 2010.

ALMEIDA, M. L. A produção de conhecimento em educação especial e a pesquisaação: contribuições para as práticas educacionais na perspectiva da inclusão escolar. In: VICTOR, S. L.; DRAGO, V. R.; PANTALEÃO, E. (Org.). Educação especial: 
indícios, registros e práticas de inclusão. 1ed.São Carlos: Pedro \&João, 2013, v. 1, p. 189-208.

ALMEIDA, M. L.; VIEIRA, A. B.; SILVA, R. R. Formação Continuada nos Municípios Capixabas: processos constituídos pelos gestores públicos em educação especial. IN: Lima-Rodrigues, L. \& Rodrigues, D. (Orgs.). Atas do III Congresso Internacional "Educação Inclusiva e Equidade". Almada, Portugal, de 31 de outubro a 2 de novembro de 2013, Pró-Inclusão: Associação Nacional de Docentes de Educação Especial.

ALMEIDA, M. L.; ZAMBON, G. F. O. Gestão da Educação Especial e Formação Continuada de Profissionais da Educação na Perspectiva da Inclusão Escolar. In: VICTOR, S. L.; OLIVEIRA, I. M. de. (Org.). Educação especial: políticas e formação de professores. Marília: ABPEE, 2016, v. 1, p. 137-158.

BARBIER, R. A pesquisa-ação. Tradução de Lucie Dibio. Brasília: Liber Libro, 2007.

BENTO, M. J. C.; SILVA, N. V. A construção de uma política pública de formação continuada de educação especial inclusiva na Região Serrana do Espírito Santo.

2015. 86 f. Trabalho de Conclusão de Curso (Graduação em Pedagogia). Universidade Federal do Espirito Santo. Vitória/ES. 2015.

BRASIL. Ministério da Educação. Conferência Mundial de Educação para Todos. Brasília, 1990. Disponível em: <http://portal.mec.gov.br/secretaria-de-educacaoespecial>. Acesso em: 16 jul 2017.

BRASIL. Ministério da Educação. Conselho Nacional de Educação. Resolução no . 2, de 11 de setembro de 2001. Institui as Diretrizes Nacionais para a Educação Especial na Educação Básica. Brasília: CNE/CEB, 2001.

BRASIL. Ministério da Educação. Ministério da Educação. Convenção sobre os Direitos das Pessoas com Deficiência. Brasília, 2007. Disponível em: <http://portal.mec.gov.br/secretaria-de-educacaoespecial>. Acesso em: 16 jul. 2017.

BRASIL. Ministério da Educação. Ministério da Educação. Política Nacional de Educação Especial na Perspectiva da Educação Inclusiva. Brasília, 2008.

BRASIL. Ministério da Educação. Conselho Nacional de Educação. Resolução nº . 4, de 2 de outubro de 2009. Institui Diretrizes Operacionais para o Atendimento Educacional Especializado na Educação Básica, modalidade Educação Especial. Brasília: CNE/CEB, 2009.

BRASIL. Ministério da Educação. Senado Federal. Lei de Diretrizes e Bases da Educação Nacional no 9394/96. Brasília, 1996. Disponível em: <http://portal.mec.gov.br/arquivos/pdf/ldb.pdf>. Acesso em: 30 jul. 2017.

CARR, W.; KEMMIS, S. Teoría crítica de la enseñanza. Barcelona: Martinez Roca, 1988. 
DALBEN, A. I. L. de F. Tensões entre formação e docência: buscas pelos acertos de um trabalho. In: DALBEN, A. I. L. de F. et al. Convergências e tensões no campo da formação e do trabalho docente. Belo Horizonte: Autêntica. 2010.

FERRARO, A. R. Diagnóstico da escolarização no Brasil. Revista Brasileira de Educação, São Paulo, n. 12, p. 22-47, 1999.

GIVIGI, R. C. do N. Tecendo redes, pescando ideias: (re)significando a inclusão nas práticas educativas na escola. 2007. 233 f. Tese (Doutorado em Educação) - Programa de Pós-Graduação em Educação, Universidade Federal do Espírito Santo, Vitória, 2007.

GONÇALVES, A. F. S. As políticas públicas e a formação continuada de professores na implementação da inclusão escolar no município de Cariacica. 356 f. Tese (Doutorado em Educação), Programa de Pós-Graduação em Educação, Universidade Federal do Espírito Santo, Vitória, 2008.

HABERMAS, J. Conhecimento e interesse. Tradução de José N. Heck. Rio de Janeiro: Guanabara, 1987a.

HABERMAS, J. Teoria de la accion comunicativa: racionalidad de la acion y racionalizacion social. Version de Manuel Jimenez Redondo. Madrid: Taurus, 1987b. v. 1.

HABERMAS, J. Teoría y práxis: estudios de filosofia social. Tradução de Salvador Mas Torres y Carlos Moya Espí. 4. ed. Madrid: Tecnos, 2000.

HABERMAS, J. Teoría y praxis: estudios de filosofia social. Tradução de Salvador MasTorres y Carlos Moya Espí. 4. ed. Madrid: Tecnos, 2002.

HABERMAS, J. Consciência moral e agir comunicativo. 2. ed. Rio de Janeiro: Tempo Brasileiro, 2003.

HABERMAS, J. Verdade e justificação: ensaios filosóficos. Tradução de Milton Camargo Mota. São Paulo: Loyola, 2004.

IMBERNÓN, F. Formação continuada de professores. Porto Alegre: Artmed, 2010.

JESUS, D. M. de (Org.). Gestão da educação especial: pesquisa, política e formação. Curitiba: Appris, 2012.

JESUS, D. M.; PANTALEAO, E.; ALMEIDA, M. L. Formação continuada de gestores públicos de Educação Especial: Políticas locais para a inclusão escolar. Archivos Analíticos de Políticas Educativas/Education Policy Analysis Archives, v. 23, p. 29, 2015.

MENDES, E. G. Breve histórico da educação especial no Brasil. Revista Educación y Pedagogía, v. 22, n. 57, p. 92-106, mayo-agosto, 2010.

MEC/SECADI. A consolidação da inclusão escolar no Brasil 2003 a 2016. Brasil, 2016. 
MOYSÉS, M. A. A. A institucionalização invisível: crianças que não aprendem na escola. Campinas: Mercado das Letras, 2013.

McLAREN, P. Multiculturalismo revolucionário: pedagogia do dissenso para o novo milênio. Porto Alegre: Artmed, 2000.

PANTALEÃO, E.; SOBRINHO, R. Escolarização de alunos com deficiência e as interrelações família, escola e gestores públicos da Educação Especial. Revista Educação Especial, v. 27, p. 171-184, 2014.

RAMOS, I. O. Educação Especial e a Superintendência Regional de Educação de Cariacica: um diálogo possível. 2011. Tese (Doutorado em Educação) Programa de Pós-Graduação em Educação, Universidade Federal do Espírito Santo, Vitória. 2011.

RAMOS, I. O.; CRUZ, S. R. I.; SILVA, R. R. O chat como espaço de diálogo: as TICs como ferramenta de formação. In: SEMINÁRIO NACIONAL DE EDUCAÇÃO ESPECIAL, 3., E SEMINÁRIO CAPIXABA DE EDUCAÇÃO INCLUSIVA, $14 .$, 2014, Vitória. Anais. Vitória: Ufes, 2014. v. 1., p. 1-8.

ROCHA, L. M. da. A gestão da Educação Especial nos municípios da área metropolitana norte de Curitiba: uma análise decorrente da Política Nacional de Educação Especial na Perspectiva da Educação Inclusiva. 2016. 181 f. Dissertação (Mestrado em Educação) - Universidade Federal do Paraná, Curitiba. 2016.

SACRISTÁN, J. G. A construção do discurso sobre a diversidade e suas práticas. In: ALCUDIA, R. et al. Tradução de Daisy Vaz de Moraes. Atenção à diversidade. Porto Alegre: Artmed, 2002. p. 13-38.

SILVA, R. R. E.; ALMEIDA, M. L. Website: desafios e possibilidades na constituição de um fórum de gestores públicos de educação especial. In: CONGRESSO BRASILEIRO DE EDUCAÇÃO ESPECIAL, 6, 2014a, São Carlos. Anais. São Carlos/SP: UFSCAR, 2014a. v. 1, p. 1-15.

SILVA, R. R. E.; ALMEIDA, M. L. A constituição de um fórum de gestores públicos de educação especial pela via website: dos desafios às possibilidades In: SEMINÁRIO NACIONAL DE EDUCAÇÃO ESPECIAL, 3., E SEMINÁRIO CAPIXABA DE EDUCAÇÃO INCLUSIVA, 14., 2014, Vitória. Anais. Vitória: Ufes, 2014b. v. 1.,p. 0115.

SILVA, R. R. Formação continuada e gestão pública de educação especial: diálogos na web. 2014. Trabalho de Conclusão de Curso (Graduação em Pedagogia) Universidade Federal do Espírito Santo. Vitória, 2014.

UNESCO. Declaração de Salamanca e linha de ação sobre necessidades educativas especiais. Salamanca, 1994.

THIOLLENT, M. Metodologia da pesquisa-ação. 7. ed. São Paulo: Cortez, 1996. 


\section{Como referenciar este artigo}

ALMEIDA, M. L.; SILVA, R. R.; ALVES, J. B. O grupo de estudo-reflexão perspectiva teórico-metodológica para Formação Continuada: um Estudo com Gestores Públicos de Educação Especial. Revista on line de Política e Gestão Educacional, Araraquara, v.21, n. esp.2, p. 1098-1118, nov. 2017. Disponível em: <http://dx.doi.org/10.22633/rpge.v21.n.esp2.2017.10184>. ISSN: 1519-9029.

Submetido em: 30/07/2017

Aprovado em: 21/09/2017 